\title{
Tandem Mass Spectrometry of Modified and Platinated Oligoribonucleotides
}

\author{
Adrien Nyakas, Silvan R. Stucki, Stefan Schürch
}

Department of Chemistry and Biochemistry, University of Bern, Freiestrasse 3, 3012 Bern, Switzerland

\begin{abstract}
Therapeutic approaches for treatment of various diseases aim at the interruption of transcription or translation. Modified oligonucleotides, such as 2'-O-methyl- and methylphosphonatederivatives, exhibit high resistance against cellular nucleases, thus rendering application for, e.g., antigene or antisense purposes possible. Other approaches are based on administration of cross-linking agents, such as cis-diamminedichloroplatinum(II) (cisplatin, DDP), which is still the most widely used anticancer drug worldwide. Due to the formation of 1,2-intrastrand cross links at adjacent guanines, replication of the double-strand is disturbed, thus resulting in significant cytotoxicity. Evidence for the gas-phase dissociation mechanism of platinated RNA is given, based on nano-electrospray ionization high-resolution multistage tandem mass spectrometry $\left(\mathrm{MS}^{n}\right)$. Confirmation was found by investigating the fragmentation pattern of platinated and unplatinated 2'-methoxy oligoribonucleotide hexamers and their corresponding methylphosphonate derivatives. Platinated 2'-methoxy oligoribonucleotides exhibit a similar gas-phase dissociation behavior as the corresponding DNA and RNA sequences, with the $3^{\prime}-\mathrm{C}-\mathrm{O}$ bond adjacent to the vicinal guanines being cleaved preferentially, leading to $w_{x}$-ion formation. By examination of the corresponding platinated methylphosphonate derivatives of the 2 '-methoxy oligoribonucleotides, the key role of the negatively charged phosphate oxygen atoms in direct proximity to the guanines was proven. The significant alteration of fragmentation due to platination is demonstrated by comparison of the fragment ion patterns of unplatinated and platinated 2'-O-methyl- and 2'-O-methyl methylphosphonate oligoribonucleotides, and the results obtained by $\mathrm{H} / \mathrm{D}$ exchange experiments.
\end{abstract}

Key words: Tandem mass spectrometry, Modified oligonucleotides, Platinated RNA, Cisplatin, Methylphosphonate, 2'-O-methyl oligoribonucleotides, Gas-phase dissociation, Hydrogen/ deuterium exchange

\section{Introduction}

A ntisense oligonucleotides (asONs) are occurring naturally and govern the cellular level of proteins by binding to a complementary segment of mRNA [1-5]. Such approach also holds huge therapeutic potential in modern

Electronic supplementary material The online version of this article (doi:10.1007/s13361-011-0106-z) contains supplementary material, which is available to authorized users.

Correspondence to: Stefan Schürch; e-mail: stefan.schuerch@ioc.unibe.ch pharmacologic applications [4, 6-10]. Antisense oligonucleotides either induce RNase $\mathrm{H}$ activity or cause steric blocking that physically disturbs splicing or even the whole translational machinery $[11,12]$. For therapeutic applications, chemical modifications are introduced in order to enhance specificity, duplex stability, and resistance of the oligonucleotides to degradation.

Methylphosphonate (MP) oligonucleotides act RNase Hindependent and have been investigated intensively, since they show reduced nonspecific mRNA interactions and offer high stability in cellular environment [13]. The 2'-position of the sugar moiety can also serve as a modification site. $2^{\prime}$-methoxy 
(2'-O-methyl) substituted oligonucleotides were found to form very stable double strands and exhibit significant nuclease resistance, which further facilitates in vivo administration [14 23].

Large-scale synthesis of as ONs for pharmaceutical applications requires reliable analytical tools for quality control. However, highly modified oligonucleotides challenge classic sequencing methods or even preclude them. A powerful tool to overcome these limitations is high-resolution tandem mass spectrometry. Analysis by mass spectrometry is independent of structural prerequisites of the oligonucleotide and uses minute amounts of sample only, e.g., in combination with a nanoelectrospray ionization (nanoESI) source. Considerable work was performed on the sequencing of unmodified oligonucleotides. Under CID conditions, DNA was found to undergo proton transfer from a phosphate group to a nucleobase, thus leading to a zwitterionic intermediate [24]. Subsequent electron rearrangement results in cleavage of the $3^{\prime}-\mathrm{C}-\mathrm{O}$ bond and the formation of a-B- and $\mathrm{w}$ - fragment ions. This mechanism was further supported by solution-phase H/D exchange (HDX) experiments performed by Gross and co-workers [25]. These experiments also revealed the influence of high proton affinity nucleobases on the fragmentation behavior of T-rich oligodeoxynucleotides. Furthermore, $\mathrm{MS}^{3}$ data were used to prove the existence of $\mathrm{x}$-ions, which were previously assigned as w$\mathrm{H}_{2} \mathrm{O}$ ions. Wan et al. used partially methylphosphonatemodified T-rich oligodeoxynucleotide sequences to localize the origin of the proton transferred upon CID of DNA [26]. Results showed that a-B-ion formation is significantly reduced if a mechanistically relevant phosphate oxygen was substituted for a methyl group, thus supporting the previously proposed mechanism.

In contrast to DNA, RNA tends to form c- and y-ions under CID conditions [27-29]. This difference is caused by the influence of the 2'-OH group, which participates in a proton transfer reaction leading to a cyclic c-ion. Such behavior was observed in negative as well as positive ion mode. Furthermore, in negative ion mode, the precursor charge state of RNA has been shown to influence fragmentation [30]. Lower charge states were found to maximize sequence coverage, whereas higher charge states favor charged base loss and promote specific dissociation channels.

Work on MS-based investigation of modified ONs has been published as well, e.g., on methylphosphonate or 2'-modified ONs [31-36]. Farand et al. used a chemical and enzymatic digestion approach to degrade random mixtures of 2'-deoxy-, 2'-fluoro-, 2'-O-methyl-, and abasic oligoribonucleotides [32, 33]. Subsequent analysis using ESI tandem mass spectrometry allowed for de-novo sequence determination of the investigated oligonucleotides. Recently, Ivleva et al. performed UHPLC/MS/MS experiments on RNA (21 mer) harboring selected modifications, such as locked nucleic acids, 2 '-fluorine or 2'-O-methyl moieties, as well as phosphorothioate linkages [37]. ONs containing 2 '-modifications were found to exhibit reduced fragmentation at the substituted positions, thus, confirming previous studies that pointed out the importance of the 2'-OH group upon gas-phase fragmentation of RNA. Wang et al. investigated the influence of 2'-O-methyl as well as methylphosphonate groups in combination with thioate linkages on the gas-phase dissociation of oligodeoxynucleotides using MALDI MS and in-source fragmentation [36]. The incorporation of a 2'-O-methyl group did not alter the fragmentation of ONs containing a thioate phosphate backbone. However, results showed that the presence of methylphosphonate (MP) groups in phosphorothioate DNA facilitates the generation of d-ions. A mechanism was proposed in which the $5^{\prime}$ MP group initiates elimination of the $4^{\prime}$-hydrogen and leads to the formation of a $\mathrm{d} / \mathrm{z}$-ion pair. Additional information about the influence of methylphosphonate linkages on the dissociation mechanism of short DNA sequences was provided by Monn and Schürch, who showed that fragmentation of MP ONs is initiated by attack of a deprotonated nucleobase on the 4'-hydrogen [34].

Other authors showed that high mass resolution in combination with high mass accuracy aids fast and unequivocal sequence determination of nucleic acids, as ambiguities in fragment ion assignment due to unresolved overlapping peak patterns are avoided [38]. Peak assignment is particularly challenging in the case of precursor ions of high charge-state bearing modifications that cause small mass shifts only.

Recently, our group presented MS/MS data on oligonucleotide cisplatin (cis-diamminedichloroplatinum(II), DDP) adducts, which exhibit an altered fragmentation pattern on the $3^{\prime}$-side adjacent to a platinated GG repeat [39]. The intensity of the $\mathrm{w}$-ion, formed by $3^{\prime}-\mathrm{C}-\mathrm{O}$ bond cleavage in direct vicinity of the platination site, was found to be elevated extraordinarily for both DNA and RNA oligonucleotides. Two fragmentation mechanisms of platinated oligonucleotides have been proposed. Evidence for the suggested dissociation pathway was found by analysis of various methylphosphonate modified oligodeoxynucleotide sequences. However, mechanistic details for the dissociation of platinated RNA remain ambiguous.

In this study, the fragmentation mechanism of platinated RNA was elucidated. Mechanistic information was obtained by analyzing methylphosphonate modified 2'-O-methyl oligoribonucleotide cisplatin adducts by nanoESI highresolution tandem mass spectrometry. The general fragmentation of 2'-O-methyl and 2'-O-methyl-methylphosphonate oligoribonucleotides was studied using multi-stage tandem mass spectrometry as well as HDX experiments, and mechanistic aspects of the dissociation of both types of modified oligoribonucleotides are discussed.

\section{Experimental}

\section{Oligonucleotides, Chemicals, and Solvents}

Desalted, single stranded (ss) modified oligonucleotides based on the sequence CCGGUU were purchased from TriLink 
Biotechnologies (San Diego, CA, USA) and used without further purification. Three of the four oligodeoxynucleotides contained methylphosphonate sites at the positions indicated by an asterisk (CC ${ }^{*} \mathrm{GGUU}, \mathrm{CC}^{*} \mathrm{G}^{*} \mathrm{GUU}, \mathrm{CCG}^{*} \mathrm{G}^{*} \mathrm{UU}$ ). Oligonucleotide solutions were prepared with concentrations of $50 \mathrm{pmol} / \mu \mathrm{L}$ in water:acetonitrile:triethylamine (49:49:2 vol/ vol/vol). HPLC grade acetonitrile (Romil Ltd., Cambridge, UK) and water (Sigma-Aldrich Chemie GmbH, Buchs, Switzerland) were used.

For $\mathrm{H} / \mathrm{D}$ exchange experiments samples were dried in a SVC-100H Savant SpeedVac and re-dissolved in $\mathrm{D}_{2} \mathrm{O}$ (99.9\%; Cambridge Isotope Laboratories, Inc., Andover, MA, USA) under nitrogen atmosphere. The oligonucleotides were stored at RT for $1 \mathrm{~h}$ and then dried again. This procedure was repeated three times to achieve a deuteration level of approximately $95 \%$.

cis-Diamminedichloroplatinum (II) (DDP) was purchased from Sigma-Aldrich Chemical Co. (St. Louis, MO, USA). Ten $\mu \mathrm{L}$ of DDP-solution $(4 \mathrm{nmol} / \mu \mathrm{L})$ was incubated with $30 \mu \mathrm{L}$ of water for $24 \mathrm{~h}$ at $37^{\circ} \mathrm{C}$ to form the reactive diaqua species $\left[\mathrm{Pt}\left(\mathrm{NH}_{3}\right)_{2}\left(\mathrm{OH}_{2}\right)_{2}\right]^{2+}$, mixed with the corresponding oligonucleotide $(1 \mathrm{nmol} / \mu \mathrm{L})$ in a molar ratio of $1.2: 1$, and incubated for another $24 \mathrm{~h}$ at $37^{\circ} \mathrm{C}$. Prior to mass spectrometric analysis, the reaction mixture was diluted with water to yield a final concentration of approximately $70 \mathrm{pmol} / \mu \mathrm{L}$.

\section{Mass Spectrometry}

All experiments were performed on a LTQ Orbitrap XL mass spectrometer (Thermo Fisher Scientific, Bremen, Germany) equipped with a nanoESI source. Oligonucleotides were analyzed in the negative ion mode with a potential of approximately $-750 \mathrm{~V}$ applied to the nanospray needle. Tandem mass spectrometric experiments were performed with the precursor ions selected within a window of $\pm 2 \mathrm{~m} / \mathrm{z}$ units. Collision-induced dissociation (CID) was performed with helium as the collision gas. Spectra were acquired over a $\mathrm{m} / \mathrm{z}$ range from 200 to 2000 . Calibration of the instrument was performed with ProteoMass LTQ/FTHybrid ESI Negative Mode Calibration Mix solution (Supelco Analytical, Bellefonte, PA, USA). The Xcalibur software package (Xcalibur 2.0.7, Thermo Fisher Scientific) was used for data processing.

\section{Results and Discussion}

Site-specific bond cleavage in proximity of the platination site is observed for RNA cisplatin adducts. To uncover the underlying gas-phase dissociation mechanism of platinated oligoribonucleotides, selected proton donor sites on the phosphate backbone were inhibited by methylphosphonate modifications. To overcome the intrinsically poor stability of methylphosphonate modified oligoribonucleotides, all 2'hydroxyl groups were substituted for 2'-O-methyl groups, resulting in considerably increased resistance against nuclease activity.

\section{Fragmentation of 2'-O-Methyl Oligoribonucleotides}

Experiments on hexaribonucleotides are based on the sequence CCGGUU, with complete substitution of the $2^{\prime}$ $\mathrm{OH}$ groups for $2^{\prime}-\mathrm{O}$-methyl modifications. Results from the unplatinated 2'-methoxy-oligoribonucleotide were compared with the findings on unmodified CCGGUU. The product ion spectrum of the latter shows a clear preference for formation of c- and y-ions (Figure 1a). In contrast, the 2'-methoxy derivative does not exhibit any preference for a certain cleavage site. The fragmentation pattern appears balanced, indicating that the backbone bonds are equally prone to dissociation (Figure 1b).

Though all members of the c- and y-ion series are present, additional ion series, e.g., $\mathrm{b} / \mathrm{x}$, and $\mathrm{a}-\mathrm{B} / \mathrm{w}$, are of comparable abundance. The pronounced loss of neutral guanine (M-G) ${ }^{3-}$ observed in the product ion spectrum of the unmodified sequence (Figure 1a) is not a preferred dissociation pathway for the 2'-methoxy derivative. Instead, loss of negatively charged uracil was detected as a minor dissociation event and signals resulting from the loss of guanine and cytosine appeared with even lower intensities. Generally, base loss is of less significance for the 2'-O-methyl modified sequence than for the unmodified oligoribonucleotide.

Since the ON is fully $2^{\prime}$-modified, the presence of uninterrupted series of c- and y-ions is remarkable, in the sense that the generally accepted mechanism for dissociation of unmodified RNA by Tromp and Schürch does not apply $[28,29]$. The mechanism assumes the 2'-hydroxyl substituent to induce cleavage of the $5^{\prime}-\mathrm{P}-\mathrm{O}$ bond, which leads to cand $\mathrm{y}$-fragment ions, whereas the c-ion rearranges to the corresponding 2'-3'-cyclic phosphate. The pathway was confirmed by MS/MS experiments on ONs carrying $2^{\prime}$ modifications and abasic sites. Findings are supported by the work of Andersen et al., who performed H/D-exchange experiments applying MALDI-TOF-MS in the positive ion mode [27]. Results obtained by pseudo $\mathrm{MS}^{3}$ experiments on c-ions agree well with the proposed cyclic structure, since the presence of a metaphosphoric acid ester group would facilitate the loss of a metaphosphoric acid $\left(\mathrm{HPO}_{3}\right)$ moiety, which was not observed.

The methoxy group at the 2'-position does not provide a bridging oxygen for the formation of a cyclic structure, thus the generation of c-and y-ions should be inhibited according to the published mechanism [29]. As this stands in contrast to our experimental data, there must be an alternative dissociation pathway accessible for 2'-O-methyl oligoribonucleotides.

Formation of c- and y-ions can be explained by the free electron pair of the phosphate oxygen rearranging randomly to either the $3^{\prime}$ - or the $5^{\prime}$-side of the oligonucleotide upon CID (Scheme 1). Subsequent cleavage of one of the $\mathrm{P}-\mathrm{O}$ 
(a)

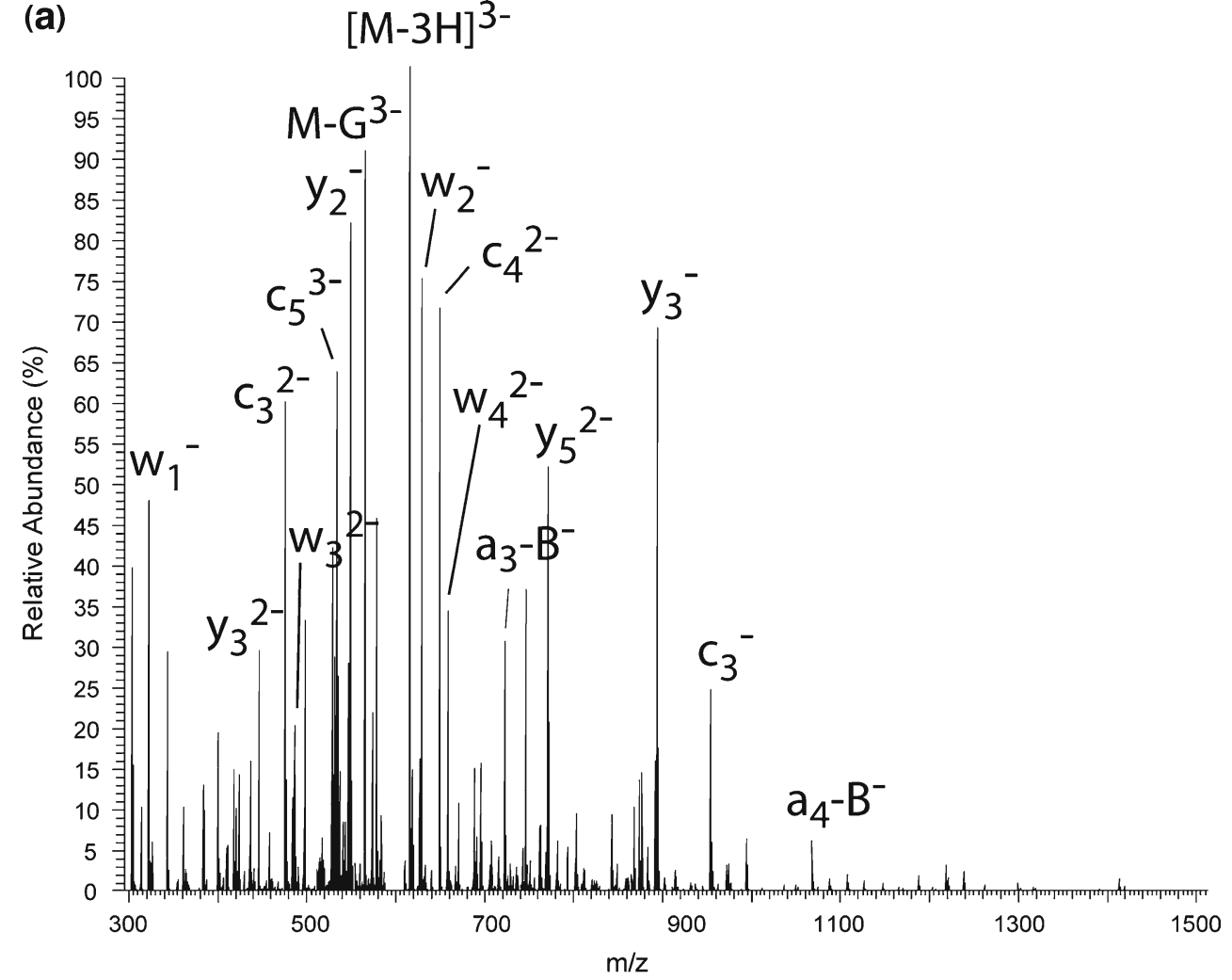

(b)

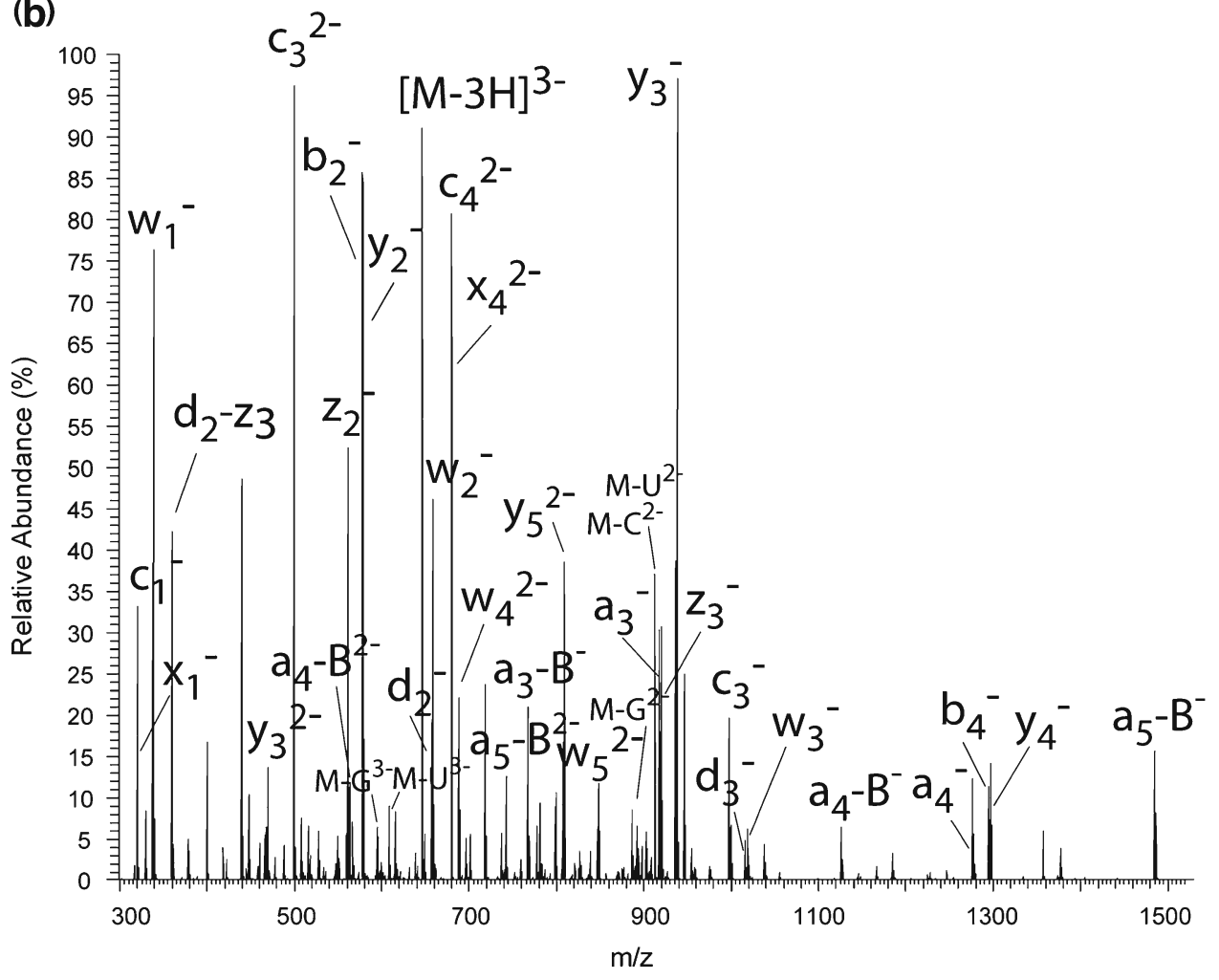

Figure 1. Product ion spectra of (a) the triply charged CCGGUU oligoribonucleotide (native) and (b) fully modified 2'-O-methyl CCGGUU. (a) exhibits a preference for the generation of $c-$ and $y$-ions, whereas the product ion spectrum of (b) reveals a balanced fragmentation pattern 


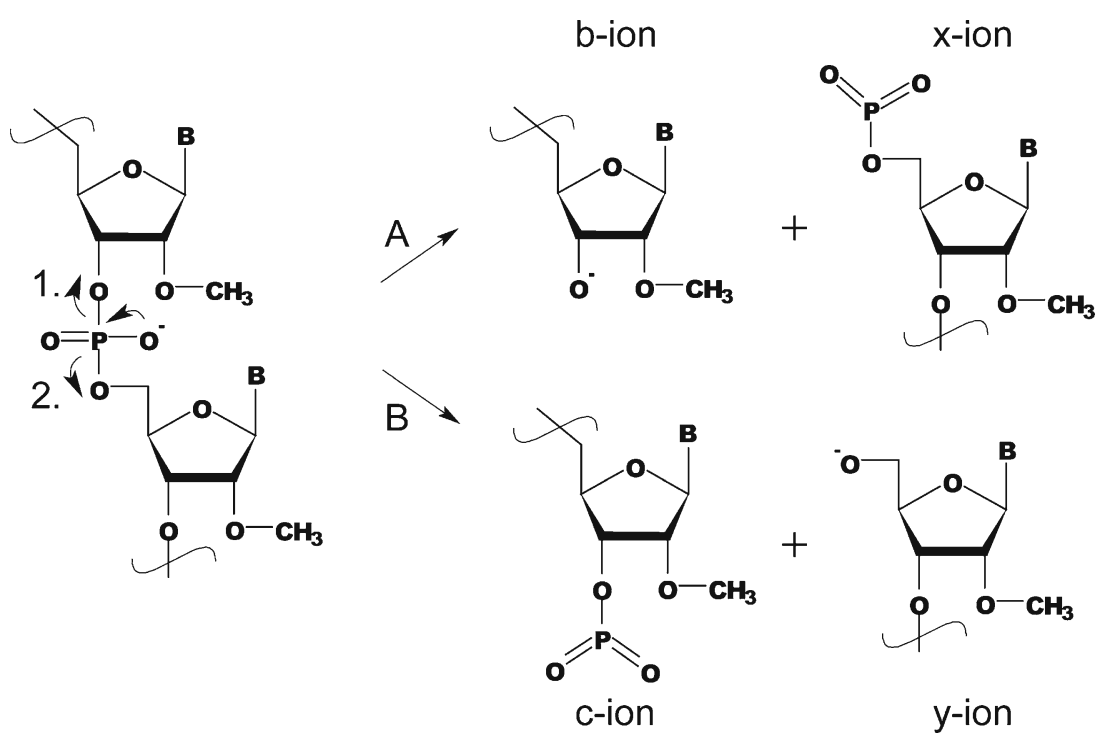

Scheme 1. Proposed gas-phase dissociation mechanism of $2^{\prime}-O-m e t h y l$ oligoribonucleotides resulting in either b/x- or $\mathrm{c} / \mathrm{y}$-ion pairs

bonds yields $\mathrm{c} / \mathrm{y}$ or $\mathrm{b} / \mathrm{x}$ ion pairs, of which the c- and $\mathrm{x}$-ions contain a metaphosphoric acid ester group. Thus, the exceptional abundance of $\mathrm{b}$ - and $\mathrm{x}$-ions, which are generated by following the dissociation pathway $\mathrm{A}$ in Scheme 1, is explained. The generation of a-B- and w-ions is not affected by the 2'-modification. Consequently, it is likely that the known DNA-typical mechanism applies to the generation of these fragments [24]. To obtain additional evidence for the mechanism proposed in Scheme 1, c- and $\mathrm{x}$-ions generated by dissociation of 2'-methoxy oligoribonucleotides were subjected to an additional activation stage in a $\mathrm{MS}^{3}$ experiment. The product ion spectra obtained by these experiments exhibit a number of internal fragment ions which were assigned as follows: the subscripted letters (a/w, b/x, c/y, d/ z) indicate the type of backbone cleavage and the capital letters represent the nucleobase(s) present. If two structures have to be considered, both possibilities are given and separated by a diagonal slash.

The $\mathrm{MS}^{3}$ product ion spectra of the $\mathrm{c}_{3}{ }^{2-}$-fragment originating from unmodified (Figure 2a) and 2'-O-methyl modified (Figure 2b) CCGGUU are depicted in Figure 2. Loss of a neutral nucleobase is the favored dissociation pathway for the unmodified $c_{3}$-ion. Loss of a metaphosphoric acid ester group $\left(\mathrm{HPO}_{3}\right)$, which would yield an $\mathrm{a}_{3}$ ion, was not observed. Also, dissociation products that unequivocally contain an $\mathrm{x}$-like cleavage site (e.g., ${ }_{\mathrm{x}} \mathrm{CG}_{\mathrm{c}}$ ) were not detected as well. These results are in good agreement with the accepted dissociation mechanism that suggests preferential formation of $2^{\prime}-3$ '-cyclic c-ions and their complementary y-ions upon gas-phase dissociation of unmodified RNA.

The $\mathrm{MS}^{3}$ spectrum of the $\mathrm{c}_{3}{ }^{2-}$-fragment originating from $2^{\prime}$-methoxy CCGGUU reveals a considerably different gasphase behavior. Cleavage of the $3^{\prime}-\mathrm{C}-\mathrm{O}$ bond resulting in $\mathrm{HPO}_{3}$ loss is indicated by the detection of the corresponding $a_{3}$-ion (bold). Furthermore, the generation of the ${ }_{y} G_{c}-$ as well as ${ }_{\mathrm{x}} \mathrm{G}_{\mathrm{c}}$-fragments gives evidence for dissociation of the $\mathrm{P}-\mathrm{O}$ bonds as suggested in Scheme 1.

The product ion spectrum of the $2^{\prime}$-modified $\mathrm{c}_{4}{ }^{2-}$-ion (Figure 3) shows internal fragment ions as predicted by the mechanism in Scheme 1. In a few cases, the structure of an internal fragment remains ambiguous, due to the presence of isobaric product ions (e.g., ${ }_{\mathrm{x}} \mathrm{B}_{\mathrm{y}} / \mathrm{b}_{\mathrm{b}}$ ). However, it is likely that both types of fragments are generated and contribute to the signal intensity. Observation of the $\mathrm{a}_{4}$-ion (bold), which is a result of $\mathrm{HPO}_{3}$ loss, is an additional indication for the presence of a metaphosphoric acid ester in the $\mathrm{c}_{4}$-ion. $\mathrm{MS}^{3}$ on the $c_{2}$-ion resulted in an $\mathrm{a}_{2}$-ion, thus giving evidence for metaphosphoric acid loss due to $3^{\prime}-\mathrm{C}-\mathrm{O}$ bond cleavage (see Supplemental, S1). Fragmentation of the $\mathrm{x}_{4}{ }^{-}$-ion, which intrinsically contains a metaphosphoric acid ester group, also resulted in loss of $\mathrm{HPO}_{3}$, yielding a $\mathrm{z}_{4}$-ion (see Supplemental, S2). However, such fragmentation pathway is not favored, thus explaining the rather low signal intensities of the corresponding a- and z-ions. The same applies to base loss, which is not very pronounced in the product ion spectra of $2^{\prime}-O$-methyl modified RNA. Instead, as for the intact $2^{\prime}$-methoxy oligoribonucleotide, dissociation into $\mathrm{c} / \mathrm{y}$ - and $\mathrm{b} / \mathrm{x}$ - type ions represents the preferred dissociation channel.

To obtain additional evidence for the fragmentation mechanism proposed in Scheme 1, hydrogen/deuterium exchange experiments in combination with tandem mass spectrometry were performed. The completely exchanged (c.e.) 2'-O-methyl oligonucleotide carrying 19 deuterium atoms was selected as the precursor ion and subjected to CID. By repetitive incubation in $\mathrm{D}_{2} \mathrm{O}$, an average deuteration level of $95 \%$ was reached for the hexamers. This resulted in overlap of the monoisotopic peak of the completely exchanged precursors with the ${ }^{13} \mathrm{C}$ isotopic peaks of the less than completely exchanged (1.t.c.e.) precursor ions. As a consequence of the 

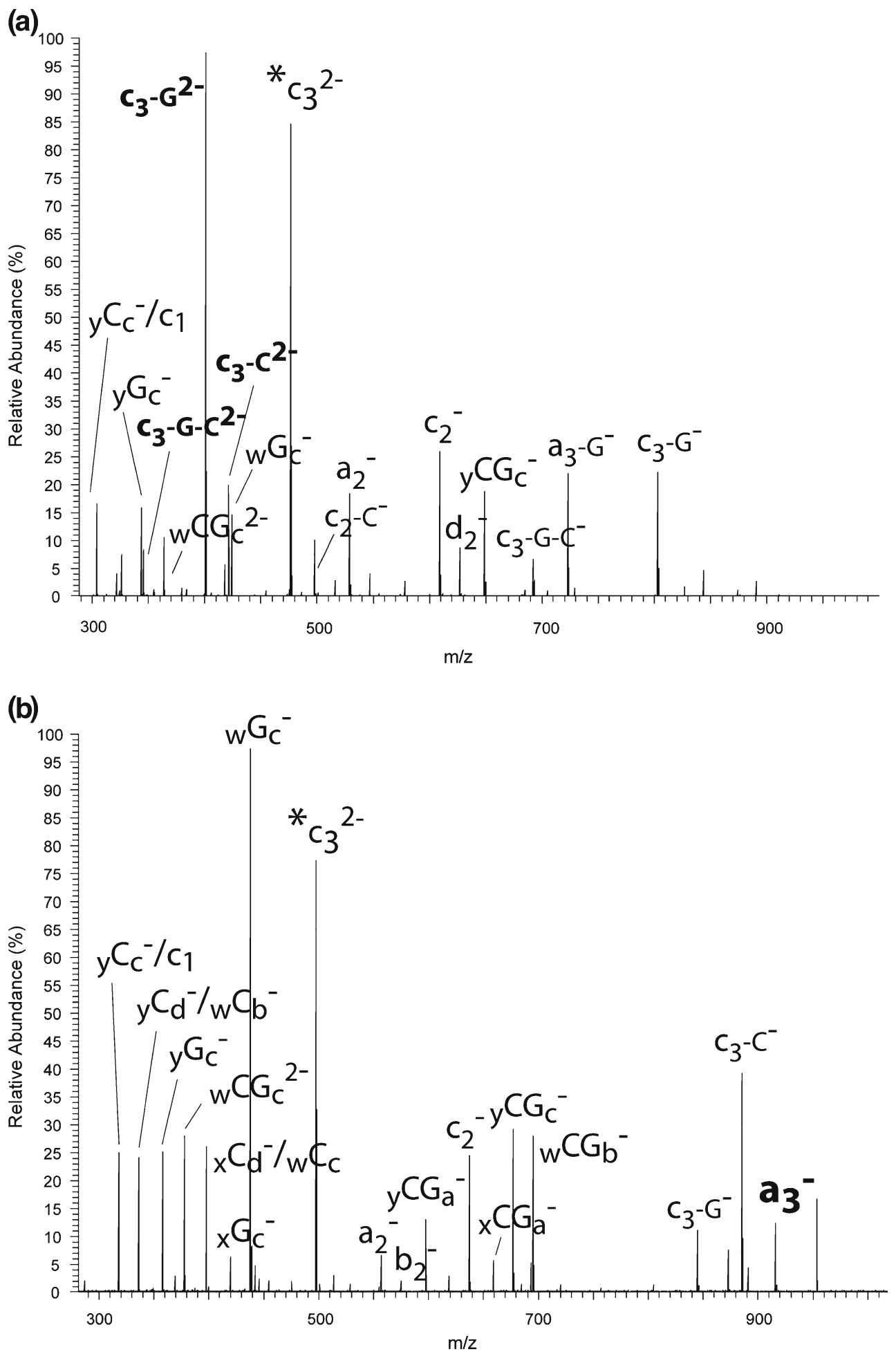

Figure 2. $\mathrm{MS}^{3}$ spectra of the $\mathrm{C}_{3}{ }^{2-}$-ion originating from unmodified (a) and $2^{\prime}-O$-methyl (b) CCGGUU (the asterisk marks the precursor ion). The unmodified c-ion (a) shows extensive neutral base loss and preferentially dissociates into c- and $y$ - type ions. CID of $2^{\prime}$-methoxy modified $\mathrm{c}_{3}{ }^{2-}$ results in the formation of both, $c / y$ and $b / x$-type fragments. Detection of the $a_{3}$-ion proves metaphosphoric acid loss and thus, the existence of a cyclic structure is precluded

unavoidable co-isolation, fragment ions always appear in both forms (c.e. and 1.t.c.e.). However, as long as no hydrogen atom in an unexchangeable position is transferred, the c.e. product ions always constitute the more abundant peak.
The proposed mechanism is based on an electron rearrangement with neither exchangeable hydrogen atoms of the backbone or the nucleobases, nor unexchangeable hydrogen atoms of the ribose being transferred. Figure 4 


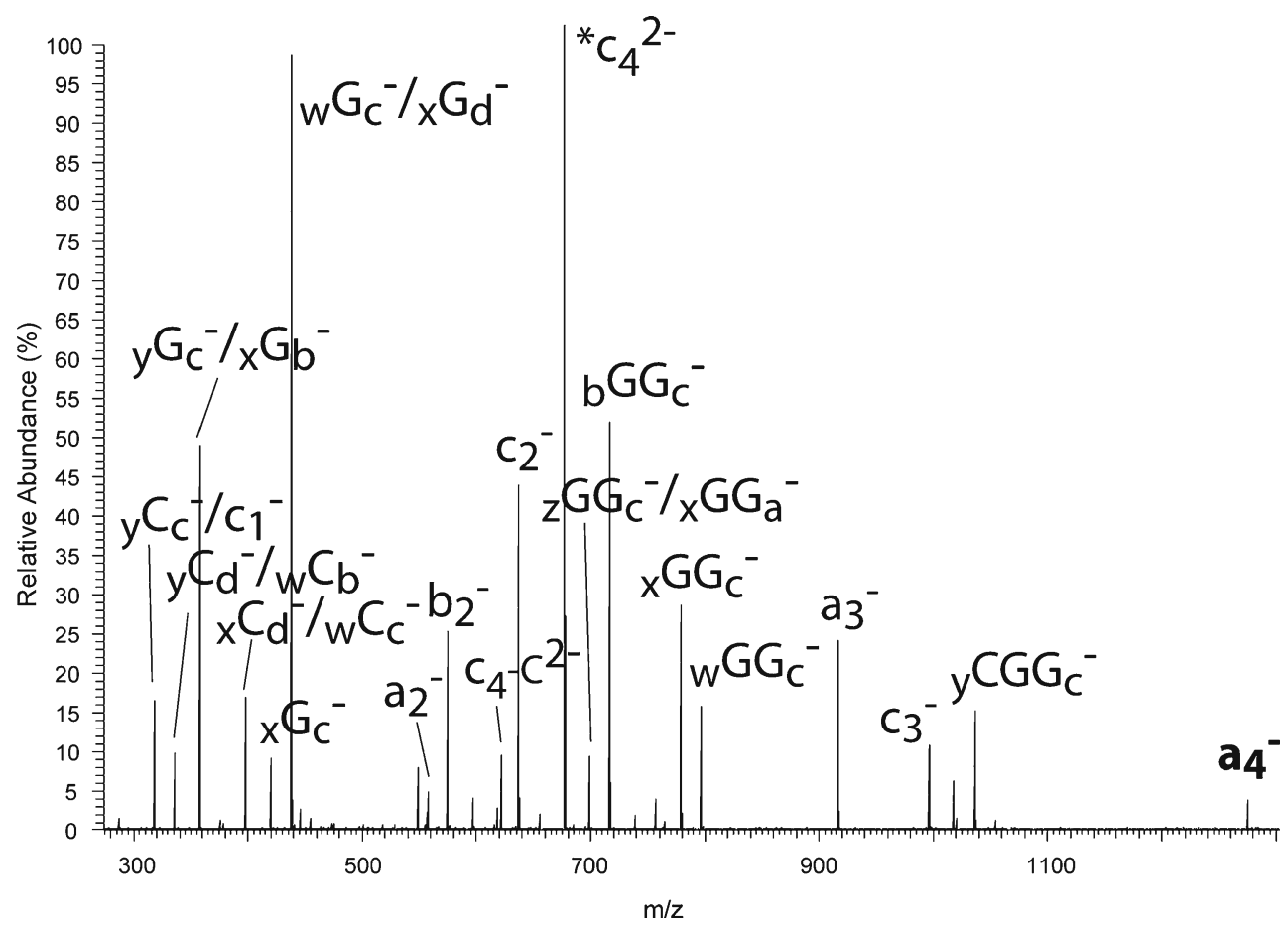

Figure 3. $\mathrm{MS}^{3}$ spectrum of the $\mathrm{C}_{4}{ }^{2-}$-ion (the asterisk marks the precursor ion) originating from $2^{\prime}$-methoxy CCGGUU, showing a clear preference for the formation of $c / y-$ and $b / x$-ion pairs. Detection of the $a_{4}$-ion after fragmentation of the modified $c_{4}{ }^{2-}-$ precursor proves loss of metaphosphoric acid and thus, a non-cyclic structure of the c-ion

shows the $\mathrm{y}_{2^{-}}, \mathrm{b}_{2^{-}}, \mathrm{x}_{4^{-}}$, and $\mathrm{c}_{4^{-}}$-ions generated by backbone dissociation of deuterated 2'-O-methyl CCGGUU according to the mechanism in Scheme 1. The completely exchanged $\mathrm{b} / \mathrm{x}-$ and $\mathrm{c} / \mathrm{y}$-ion series are generally of considerable higher intensity than the corresponding 1.t.c.e. fragments.

The situation changes for the a-B- and w-ion series. Formation of the a-B-ion involves transfer of the unexchangeable $4^{\prime}$-hydrogen to an exchangeable phosphate hydrogen [24]. Since the corresponding phosphate group now carries a hydrogen, the 1 1.t.c.e. a-B-fragment ions gain abundance. In analogy, the 2'-hydrogen of the ribose is transferred to the phosphate group of the complementary wfragment ion, thus, generating the 1 l.t.c.e. w-ion. Such proton transfer is reflected by a significantly reduced ratio of the c.e. to the 1.t.c.e. fragment ion peaks, compared to the $b /$ $\mathrm{x}-$ and $\mathrm{c} / \mathrm{y}$-ion signals (Supplemental S3). Consequently, these results are consistent with the proposed dissociation pathway.

The dissociation mechanism found for triply deprotonated 2'-O-methyl CCGGUU (Scheme 1), persists upon CID of the doubly charged precursor (see Supplemental, S4). The generated fragment ions are very similar, though the precursor harboring two negative charges shows a preference for the formation of singly charged fragment ions and the generation of a-B/w-ion pairs is slightly decreased. Additionally, the formation of d-and z-ions is less pronounced, indicating that the formation of $\mathrm{c} / \mathrm{y}$ - as well as $\mathrm{b} / \mathrm{x}$-ion pairs represents the lowest energy dissociation channel for 2'-methoxy oligoribonucleotides. The product ion spectrum of the quadruply charged precursor provides limited sequence information. This observation is in agreement with the data by McLuckey and coworkers [30], who found that low charge-states and low excitation amplitudes favor cleavage of the $5^{\prime}-\mathrm{C}-\mathrm{O}$ bond of RNA, which results in c/y-ion pairs, whereas high precursor charge states trigger few dissociation channels only, resulting in restricted sequence coverage.

\section{Fragmentation of Platinated 2'-O-Methyl Oligoribonucleotides}

Platination was found to alter the fragmentation of oligodeoxynucleotides considerably, in the sense that the $3^{\prime}-\mathrm{C}-\mathrm{O}$ bond adjacent to the cisplatin adduct is preferentially cleaved upon CID [39].

In the current study, 2'-O-methyl modified cisplatin adducts of the oligoribonucleotide CCGGUU reveal that the 2'-methoxy modification does not inhibit the preferred dissociation of the $3^{\prime}-\mathrm{C}-\mathrm{O}$ bond in proximity of the platination site. Hence, increased formation of the $\mathrm{w}_{2}$ $\left(=\mathrm{w}_{\mathrm{x}}\right)$-ion is observed. In the following paragraphs, w-ions, which are formed due to cleavage at this specific position, are referred to as $\mathrm{w}_{\mathrm{x}}$-ions.

In general, product ion spectra of platinated 2'-O-methyl oligoribonucleotides reveal fewer fragments and the previously observed balanced dissociation of unplatinated 2'-O-methyl oligonucleotides is shifted towards increased formation of a-B-, $\mathrm{a}-, \mathrm{w}-, \mathrm{d}-$, and z-ions. The $\mathrm{w}_{2}$-ion intensity is elevated, as for unmodified platinated RNA hexamers. Moreover, the comple- 


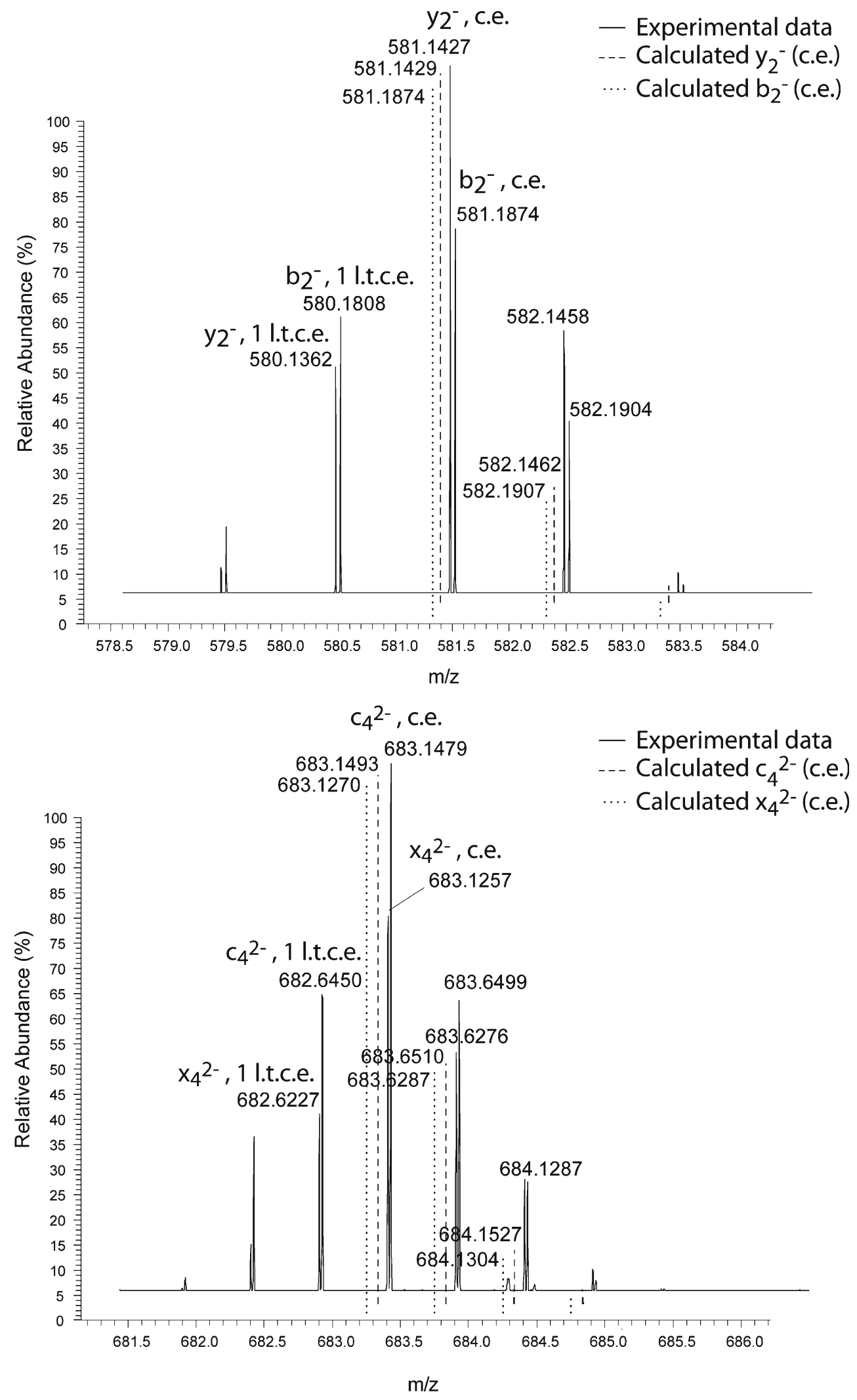

Figure 4. Enlarged sections of the $\mathrm{b}_{2}{ }^{-} / \mathrm{y}_{2}{ }^{-}$as well as $\mathrm{C}_{4}{ }^{2-} / \mathrm{x}_{4}{ }^{2-}$ signals after HDX experiments with $2^{\prime}-$ methoxy CCGGUU. The c.e. peak does always exceed the 1 l.t.c.e. signal, thus supporting the assumption that proton transfer reactions are not carried out during fragmentation 
mentary $\left[\mathrm{a}_{4}+\mathrm{Pt}\right]$-ion constitutes the most abundant platinated fragment (Figure 5).

Additionally, the $\mathrm{a}_{3}$-B-ion was detected, giving evidence for 2'-O-methyl oligoribonucleotides dissociating according to the previously proposed mechanism, which describes the dissociation of unmodified platinated DNA [39]. The only cleavage product that is absent throughout all product ion spectra of platinated 2'-O-methyl oligoribonucleotides is the $\mathrm{a}_{4}$-B-ion, which would be formed by decomposition of $\left[\mathrm{a}_{4}+\right.$ Pt] under release of a $[\mathrm{G}+\mathrm{Pt}]$-fragment.

A deprotonated phosphate group is playing the key role in each step of the dissociation cascade. Upon CID, protons are abstracted from either the $4^{\prime}$ - or the $2^{\prime}$-position of the sugar. Since the $\mathrm{d}_{2}$ - and the $\mathrm{d}_{3}$-ion signals are considerably increased compared with the product ion spectrum of the unplatinated 2'-methoxy sequence, another pathway seems to be favored. Considering the fact that the negative charge can alternatively be located on the nucleobases, there exist two potential mechanisms for the formation of d- and z-ions (Scheme 2). They both include abstraction of the 4'-hydrogen, which induces cleavage of the $5^{\prime}-\mathrm{C}-\mathrm{O}$ bond, thus generating a d-/z-ion pair. Proton abstraction may be carried out by either a nucleobase (step A in Scheme 2) or a deprotonated phosphate oxygen (step B in Scheme 2).

\section{Fragmentation of Platinated 2'-O-Methyl- Methylphosphonate Oligoribonucleotides}

The role of the phosphate group in the extraordinarily increased formation of the $\mathrm{w}_{\mathrm{x}}$-ion upon fragmentation of platinated 2'-O-methyl-methylphosphonate oligoribonucleo-
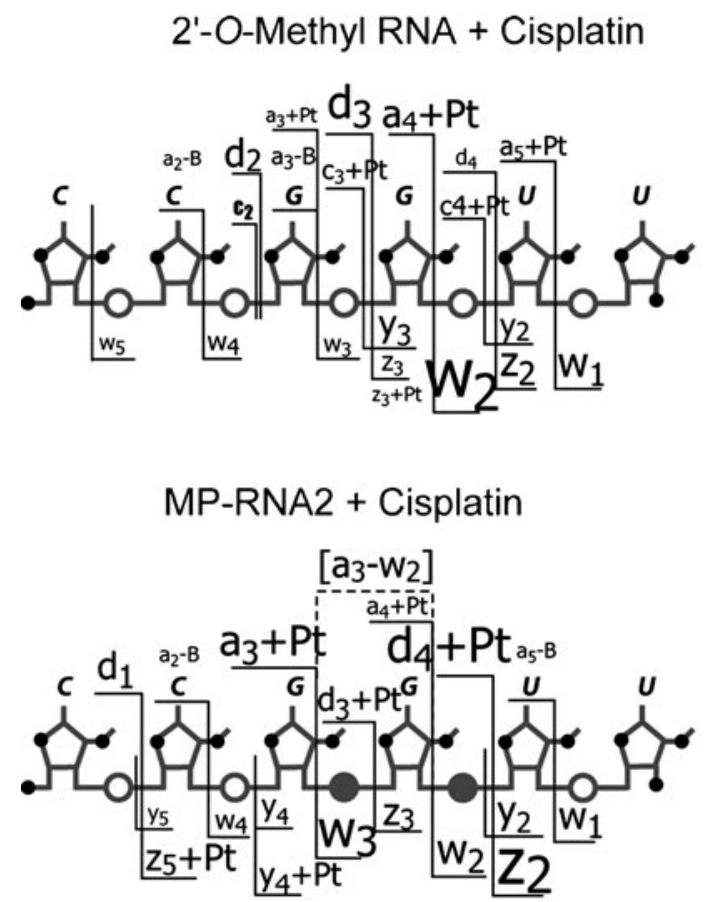

tides was investigated by subjecting the cisplatin adducts of MP-RNA1 (CC* $\left.\mathrm{G}^{*} \mathrm{GUU}\right)$ and MP-RNA2 (CCG*G*UU), carrying additional vicinal methylphosphonate linkages, to CID (the asterisk marks the methylphosphonate substitution). According to the proposed dissociation pathways [39], inactivation of mechanistically crucial phosphate groups blocks the formation of the $\mathrm{w}_{\mathrm{x}}$-ion. These findings were confirmed by experiments on platinated MP-RNA1 and MPRNA2, which gave no evidence for the predominant formation of the $\mathrm{w}_{2}$-ion (Figure 5). Since, the intensity of the $\mathrm{w}_{2}$-ion signal does not change after the addition of cisplatin, the generation of the $\mathrm{w}_{2}$-fragment must result from attack of the uracil base on the $4^{\prime}$-hydrogen of the adjacent $5^{\prime}$-sugar residue according to the mechanism proposed by Monn and Schürch [34].

MP-RNA3 (CC*GGUU) comprises a single methylphosphonate modification in a remote position from the cleavage site, thus not restricting $\mathrm{w}_{2}$-ion formation. The corresponding product ion spectrum shows the $\mathrm{w}_{2}$-ion and the complementary $\left[\mathrm{a}_{4}+\mathrm{Pt}\right]$-fragment with high abundances, thus pointing out the key role the phosphate groups between the two guanosines and on the 3'-side of the GG repeat are playing upon formation of the $\mathrm{w}_{2}$-ion.

Data give strong evidence that the dissociation mechanisms of platinated DNA also apply to RNA-cisplatin adducts [39]. This fact is remarkable, since the inherent fragmentation behavior of the two types of oligonucleotides is fundamentally different. Platination does not only promote the formation of $\mathrm{w}_{\mathrm{x}}$-ions, it also facilitates $\mathrm{d}$ - and $\mathrm{z}$-ion generation in the vicinity of the cisplatin adduct for 2'methoxy oligoribonucleotides and their methylphosphonate
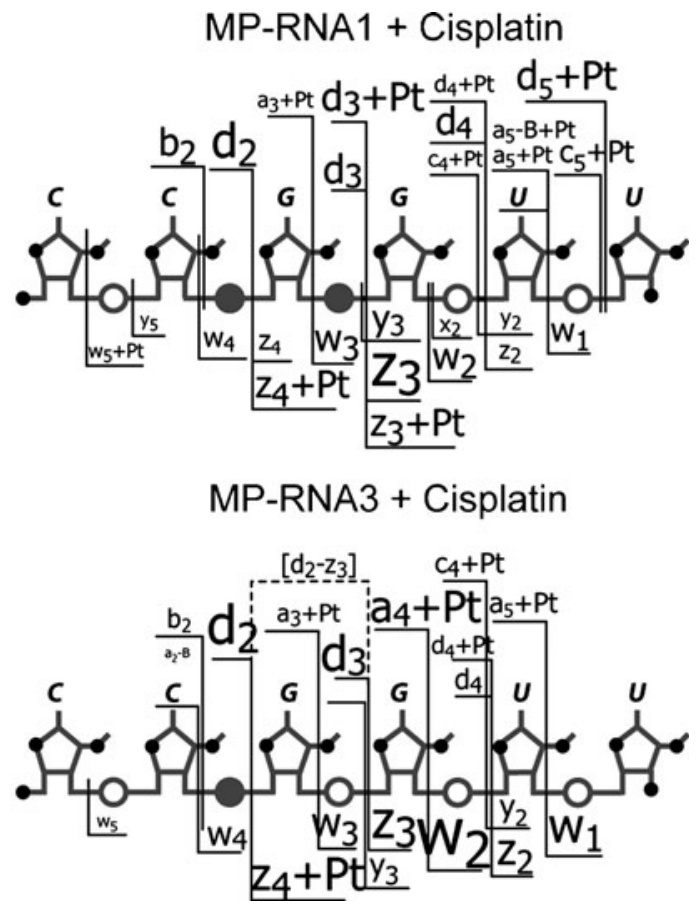

Figure 5. Observed fragments of platinated 2'-O-methyl CCGGUU and its corresponding methylphosphonate derivatives. Square brackets indicate internal fragments. Fragment ion intensities are indicated by font size 


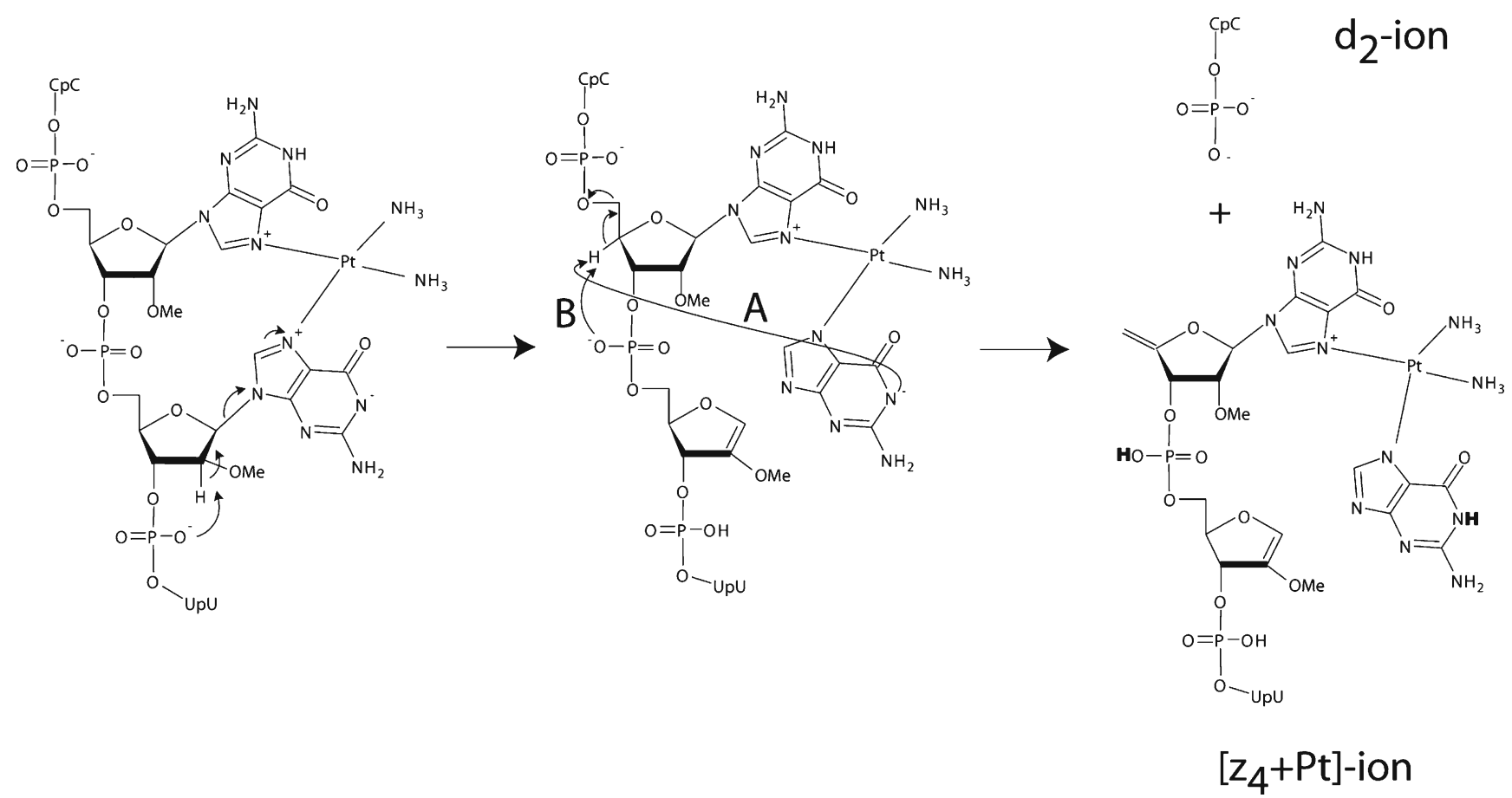

Scheme 2. Alternative dissociation pathways of platinated 2 '-O-methyl oligoribonucleotides resulting in $d-$ and $[z+P t]$-ions

derivatives. Apart from the prominent $\mathrm{w}_{2}$ and $\left[\mathrm{a}_{4}+\mathrm{Pt}\right]$-ions, the $d_{2}-/ z_{4}-$ and $\left[z_{4}+P t\right]-$, as well as the $d_{3}-/ z_{3}-$ and $\left[z_{3}+P t\right]-$ ion pairs constitute the most abundant fragments of both platinated MP-RNA1 and platinated MP-RNA2. The pronounced generation of $\mathrm{d}$-/z-ion pairs in proximity of the platination site of 2-methoxy- as well as 2-methoxy methylphosphonate oligoribonucleotides suggests that fragmentation pathway A in Scheme 2 is preferred over pathway B. Consequently, the negatively charged guanine on the $\left[\mathrm{a}_{4}+\mathrm{Pt}\right]$-fragment is most likely abstracting the $4^{\prime}$-hydrogen of the sugar residue on the adjacent 5 '-side to form d- and zions, rather than releasing a guanine-cisplatin adduct under formation of the corresponding $\mathrm{a}_{4}$-B-ion.

Hence, an elevated d- and z-ion abundance in combination with increased w-ion generation serve as supplementary markers for GG repeats in the sequence of platinated 2'methoxy oligonucleotides. Comparison of unplatinated and platinated sequences reveals the impact of the cisplatin moiety on the gas-phase dissociation of platinated MP-RNA.

\section{Fragmentation of Unplatinated 2'-O-Methyl- Methylphosphonate Oligoribonucleotides}

The presence of additional methylphosphonate linkages changes the balanced dissociation of unplatinated 2'-methoxy oligoribonucleotides and gives rise to characteristic and sitespecific ion patterns (Figure 6). The methylphosphonate linkages constitute the favored cleavage sites, generating mostly d- and z-ions. By substituting methylphosphonates for the two phosphate groups the formation of c-, y-, and $\mathrm{x}$-ions in the proximity of the modification is suppressed completely.
Thus, it is very likely that $\mathrm{c}-\mathrm{y}-\mathrm{y}$ - and $\mathrm{b}-\mathrm{x}$-ion formation is initiated by electron rearrangement originating from the negatively charged phosphate oxygen, as shown in Scheme 1. Fragment ions observed for the three methylphosphonatemodified 2'-O-methyl oligoribonucleotides investigated indicate that formation of d-and z-ions is induced by attack of the 3 '-adjacent unmodified phosphate group on the 4'-hydrogen of the sugar moiety (Scheme 3).

The $\mathrm{d}-\mathrm{z}$-ion pair formed by cleavage of the $5^{\prime}-\mathrm{C}-\mathrm{O}$ bond of the methylphosphonate group exhibits the most intensive signal within the whole $\mathrm{d} / \mathrm{z}$-ion series, thus the signals of the $d_{3} / z_{3}-$ and the $d_{4} / z_{2}$-ion pairs of MP-RNA1 and MP-RNA2, respectively, are very prominent. If the attack were carried out by the nucleobase, bond cleavage at the methylphosphonate sites would be expected to occur to the same extent. At first sight, MP-RNA3 seems to show a different behavior, since it does not generate the expected strong $\mathrm{d}_{2} / \mathrm{z}_{4}$-ion pair signal. Pronounced $\mathrm{d}_{2}$ - and $\mathrm{z}_{3}$-peaks are observed whereas the $\mathrm{z}_{4}$-ion lacks completely. However, an abundant peak originating from the internal $\left[\mathrm{d}_{2}: \mathrm{Z}_{3}\right]$-fragment is detected, indicating secondary decomposition of the previously formed $\mathrm{z}_{4}$-ion.

As described above, backbone cleavage can be induced by the nucleobase attacking the $4^{\prime}$-hydrogen and subsequent $\beta$-elimination, which finally results in the $\mathrm{d}-/ \mathrm{z}-$ and $\mathrm{a}-\mathrm{w}$-ion pairs. Backbone cleavage occurs on the 5 '-side of the two methylphosphonate groups, which are unable to carry out proton transfer. In this case, the nearby guanine most likely serves as the origin of the dissociation cascade.

The formation of a- and w-ions is the predominant dissociation event of MP-RNA2 (Figure 6). The $d_{3}$-fragment 


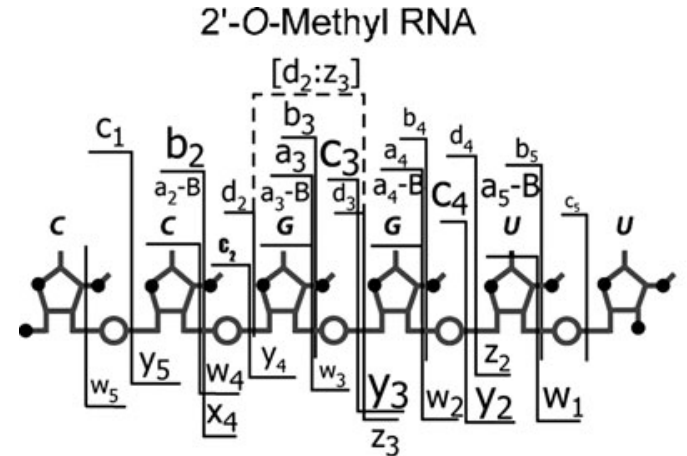

MP-RNA2

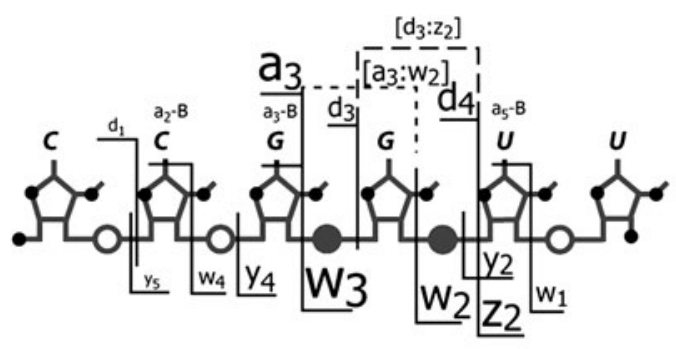

MP-RNA1

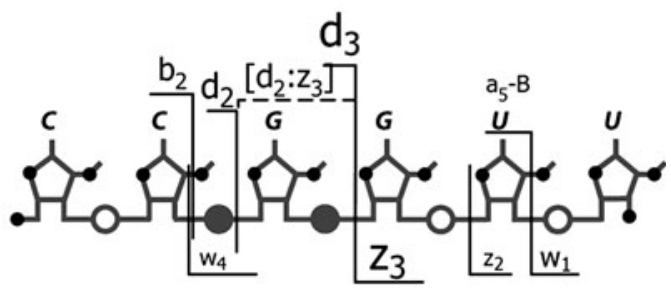

MP-RNA3

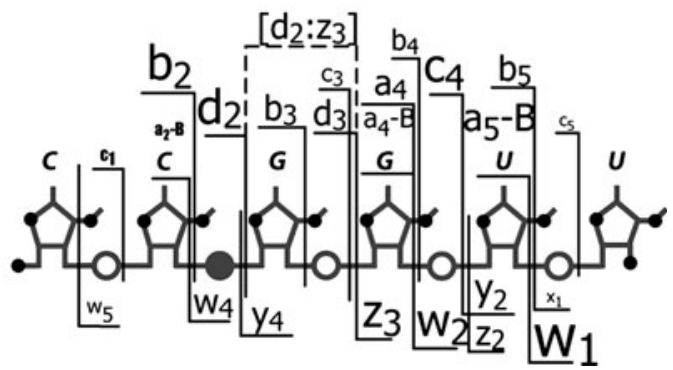

Figure 6. Observed fragments of 2'-O-methyl CCGGUU and its methylphosphonate derivatives. Square brackets indicate internal fragments. Fragment ion intensities are indicated by font size
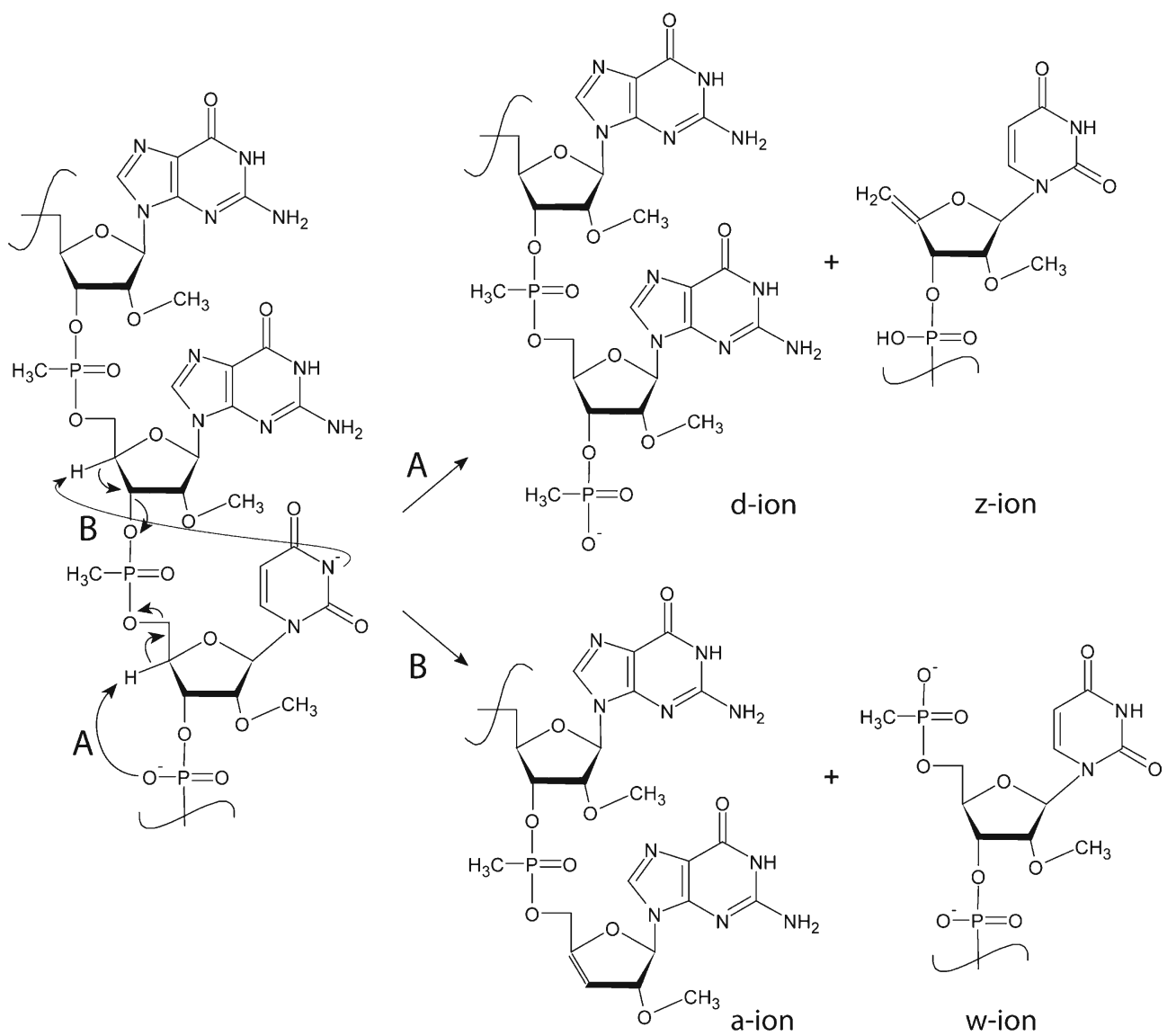

Scheme 3. Proposed mechanism for the gas-phase dissociation of 2'-O-methyl methylphosphonate oligoribonucleotides in proximity of the MP linkage 
is observed, though the complementary $z_{3}$-ion is not found in the spectrum. Instead, an abundant peak at $\mathrm{m} / \mathrm{z} 356.076$ was detected. This peak has to originate from one of the internal fragments $\left[\mathrm{a}_{3}: \mathrm{w}_{2}\right]$, or $\left[\mathrm{d}_{3}: \mathrm{Z}_{2}\right]$. Both fragments exhibit identical elemental composition $\left(\mathrm{C}_{11} \mathrm{H}_{12} \mathrm{~N}_{5} \mathrm{O}_{7} \mathrm{P}\right)$, thus rendering direct identification by mass spectrometry impossible. Nevertheless, the complete absence of the $a_{4^{-}}$and $z_{3}$-ions, which are complementary to the observed $\mathrm{w}_{2}$ - and $\mathrm{d}_{3}$-fragments, respectively, indicates that both internal fragments $\left(\left[\mathrm{a}_{3}: \mathrm{w}_{2}\right],\left[\mathrm{d}_{3}: \mathrm{z}_{2}\right]\right)$ contribute to the peak at $\mathrm{m} / \mathrm{z} 356.076$.

As for d-/z-ion formation, nucleobase attack does also lead to the generation of a- and w-ions for MP modified 2'$O$-methyl oligoribonucleotides. The negatively charged nucleobase only is able to induce proton transfer reactions in proximity of the modification site. In the corresponding dissociation mechanism (Scheme 3), the electron pair of the 4 '-hydrogen is migrating towards the $3^{\prime}$-end, thus, inducing cleavage of the $3^{\prime}-\mathrm{C}-\mathrm{O}$ bond.

Additional proof for the mechanism was obtained by HDX and MS/MS experiments performed on 2'-O-methylmethylphosphonate oligoribonucleotides. According to the mechanism in Scheme 3, w- and z-ions carry one deuterium atom less than the c.e. fragments, due to abstraction of the 4'-hydrogen atoms during fragmentation; a- and d-ions, though, carry the maximum number of deuterium atoms, since exchangeable protons are not transferred. MS/MS data agree well with the proposed mechanisms as, e.g., the c.e. $\mathrm{d}_{3}$-ion $(\mathrm{m} / \mathrm{z} 508.6309)$ and the 1 1.t.c.e. $\mathbf{z}_{3}$-ion $(\mathrm{m} / \mathrm{z} 924.2065)$ represent by far the most intensive peaks in the product ion spectrum of MP RNA 1 (see Supplemental S5 and S6). The product ion spectra of MP-RNA 2 and MP-RNA 3 further support these findings. Due to decomposition, detection of the $z_{4}$-ion of MP-RNA 3 is not possible. Confirmation was found by observation of an ion with $\mathrm{m} / \mathrm{z} 361.0738$, which agrees well with the calculated mass of the 1 l.t.c.e. $\left[\mathrm{d}_{2}: \mathrm{z}_{3}\right]$ internal fragment. This result is consistent with the proposed $\mathrm{d} / \mathrm{z}$-ion formation by an attack from the 5 '-adjacent phosphate group. If the $\mathrm{z}_{4}$-ion decomposes further, the internal fragment has to harbor the previous 4'-hydrogen of the sugar ring and, hence, yield the 1 1.t.c.e. fragment ion.

Given the fact that dominant fragment ions exhibiting a higher mass than expected are not found throughout all product ion spectra of 2'-O-methyl- and 2'-O-methylmethylphosphonate oligoribonucleotides, alternative dissociation mechanisms, in which exchangeable protons (e.g., of the phosphate groups or the nucleobases) are participating, can be excluded.

\section{Conclusions}

Evidence for the dissociation mechanism of short platinated RNA was found by investigation of 2'-methoxy-oligoribonucleotides cisplatin adducts and their methylphosphonate analogues. Complete substitution of the RNA 2'-hydroxyl group by a $2^{\prime}$-methoxy group does not result in an altered dissociation behavior of short platinated oligoribonucleoti- des, thus proving that the 2 '-hydroxyl group is not involved in the fragmentation mechanism. A dissociation mechanism explaining the increased generation of $\mathrm{d}$ - and z-ions in the proximity to the GG cisplatin moiety for 2'-methoxy- and 2'methoxy methylphosphonate oligoribonucleotides is proposed. The negatively charged guanine and deprotonated phosphate oxygen atoms are responsible for initiation of proton transfer reactions leading to subsequent bond cleavage. Unplatinated 2'-O-methyl oligonucleotides show a balanced dissociation upon CID, with a preference for $\mathrm{c} / \mathrm{y}-$ and $\mathrm{b} / \mathrm{x}$-ion pairs in case of lower charged precursors, and the observed similar abundance of c-/y- and b-/x-ion pairs is explained. $\mathrm{MS}^{3}$ data reveal that the observed preference for the c-, y-, b-, and x-ions is the result of an either 5'- or 3'directed electron rearrangement of the corresponding phosphate oxygen. Additional evidence for the proposed dissociation mechanisms is provided by the results of $H / D$ exchange experiments.

This work demonstrates the versatility of tandem mass spectrometry as a tool for sequence analysis of therapeutically relevant, highly modified oligonucleotides. The technique can thus support the establishment of quality control protocols for chemically altered oligonucleotides applied to antisense, antigene, and other strategies related to in vivo manipulation of nucleic acids.

\section{Acknowledgments}

The authors gratefully acknowledge financial support of this work by the Swiss National Science Foundation (grants no. 200020_121843 and 206021_121304).

\section{References}

1. Helene, C., Toulme, J.J.: Specific regulation of gene-expression by antisense, sense, and antigene nucleic acids. Biochim. Biophys. Acta 1049, 99-125 (1990)

2. Weintraub, H.M.: Antisense RNA and DNA. Sci. Am. 262, 40-46 (1990)

3. Dias, N., Stein, C.A.: Antisense oligonucleotides: basic concepts and mechanisms. Mol. Cancer Ther. 1, 347-355 (2002)

4. Masaki, Y., Miyasaka, R., Ohkubo, A., Seio, K., Sekine, M.: Linear relationship between deformability and thermal stability of 2'-Omodified RNA hetero duplexes. J. Phys. Chem. B 114, 2517-2524 (2010)

5. Milligan, J.F., Matteucci, M.D., Martin, J.C.: Current concepts in antisense drug design. J. Med. Chem. 36, 1923-1937 (1993)

6. Jorgensen, R.: Altered gene-expression in plants due to trans interaction between homologous genes. Trends Biotechnol. 8, 340-344 (1990)

7. Romano, N., Macino, G.: Quelling transient inactivation of geneexpression in Neurospora crassi by transformation with homologous sequences. Mol. Microbiol. 6, 3343-3353 (1992)

8. Fire, A., Xu, S.Q., Montgomery, M.K., Kostas, S.A., Driver, S.E., Mello, C.C.: Potent and specific genetic interference by double-stranded RNA in Caenorhabditis elegans. Nature 391, 806-811 (1998)

9. Guntaka, R.V., Varma, B.R., Weber, K.T.: Triplex-forming oligonucleotides as modulators of gene expression. Int. J. Biochem. Cell Biol. 35, 22-31 (2003)

10. De Rosa, G., La Rotonda, M.I.: Nano and microtechnologies for the delivery of oligonucleotides with gene silencing properties. Molecules 14, 2801-2823 (2009)

11. Giles, R.V., Tidd, D.M.: Increased specificity for antisense oligodeoxynucleotide targeting of RNA cleavage by RNase H using chimeric methylphosphodiester phosphodiester structures. Nucleic Acids Res. 20, 763-770 (1992) 
12. Ghosh, M.K., Cohen, J.S.: Oligodeoxynucleotides as antisense inhibitors of gene-expression. Prog. Nucleic Acid Res. Mol. Biol. 42, 79-126 (1992)

13. Miller, P.S., Yano, J., Yano, E., Carroll, C., Jayaraman, K., Tso, P.O.P.: Non-ionic nucleic-acid analogs-synthesis and characterization of dideoxyribonucleoside methylphosphonates. Biochemistry 18, 51345143 (1979)

14. Kawai, G., Yamamoto, Y., Kamimura, T., Masegi, T., Sekine, M., Hata, T., Iimori, T., Watanabe, T., Miyazawa, T., Yokoyama, S.: Conformational rigidity of specific pyrimidine residues in transfer-RNA arises from post-transcriptional modifications that enhance steric interaction between the base and the 2'-hydroxyl group. Biochemistry 31, 10401046 (1992)

15. Kawasaki, A.M., Casper, M.D., Freier, S.M., Lesnik, E.A., Zounes, M. C., Cummins, L.L., Gonzalez, C., Cook, P.D.: Uniformly modified 2'deoxy-2'-fluoro phosphorothioate oligonucleotides as nuclease-resistant antisense compounds with high-affinity and specificity for RNA targets. J. Med. Chem. 36, 831-841 (1993)

16. Saneyoshi, H., Seio, K., Sekine, M.: A general method for the synthesis of 2 - $O$-cyanoethylated oligoribonucleotides having promising hybridization affinity for DNA and RNA and enhanced nuclease resistance. $J$. Org. Chem 70, 10453-10460 (2005)

17. Bonham, M.A., Brown, S., Boyd, A.L., Brown, P.H., Bruckenstein, D.A., Hanvey, J.C., Thomson, S.A., Pipe, A., Hassman, F., Bisi, J.E., Froehler, B. C., Matteucci, M.D., Wagner, R.W., Noble, S.A., Babiss, L.E.: An assessment of the antisense properties of RNase H-competent and stericblocking oligomers. Nucleic Acids Res. 23, 1197-1203 (1995)

18. Prakash, T.P., Bhat, B.: 2'-modified oligonucleotides for antisense therapeutics. Curr. Top. Med. Chem. 7, 641-649 (2007)

19. Barbe, S., Le Bret, M.: Effect of a water molecule on the sugar puckering of uridine, $2^{\prime}$-deoxyuridine, and $2^{\prime}$ - $O$-methyl uridine inserted in duplexes. J. Phys. Chem. A 112, 989-999 (2008)

20. Cheng, D.M., Sarma, R.H.: Nuclear magnetic-resonance study of impact of ribose $2^{\prime}-O$-methylation on aqueous-solution conformation of cytidylyl-(3'-]5')-cytidine. Biopolymers 16, 1687-1711 (1977)

21. Kool, E.T.: Preorganization of DNA: design principles for improving nucleic acid recognition by synthetic oligonucleotides. Chem. Rev. 97, 1473-1487 (1997)

22. Kiblerherzog, L., Zon, G., Uznanski, B., Whittier, G., Wilson, W.D.: Duplex stabilities of phosphorothioate, methylphosphonate, and RNA analogs of 2 DNA 14-mers. Nucleic Acids Res. 19, 2979-2986 (1991)

23. Dunlap, B.E., Frideric, K.H., Rottman, F.: 2'-O-methyl polynucleotides as templates for cell-free amino acid incorporation. Biochemistry 10, 2581-2587 (1971)

24. Wang, Z., Wan, K.X., Ramanathan, R., Taylor, J.S., Gross, M.L.: Structure and fragmentation mechanisms of isomeric T-Rich oligodeoxynucleotides: a comparison of four tandem mass spectrometric methods. J. Am. Soc. Mass Spectrom. 9, 683-691 (1998)

25. Wan, K.X., Gross, J., Hillenkamp, F., Gross, M.L.: Fragmentation mechanisms of oligodeoxynucleotides studied by H/D exchange and electrospray ionization tandem mass spectrometry. J. Am. Soc. Mass Spectrom. 12, 193-205 (2001)

26. Wan, K.X., Gross, M.L.: Fragmentation mechanisms of oligodeoxynucleotides: effects of replacing phosphates with methylphosphonates and thymines with other bases in T-rich sequences. J. Am. Soc. Mass. Spectrom. 12, 580-589 (2001)

27. Andersen, T.E., Kirpekar, F., Haselmann, K.F.: RNA fragmentation in MALDI mass spectrometry studied by H/D-exchange: mechanisms of general applicability to nucleic acids. J. Am. Soc. Mass Spectrom. 17, 1353-1368 (2006)

28. Tromp, J.M., Schürch, S.: Electrospray ionization tandem mass spectrometry of biphenyl-modified oligo(deoxy)ribonucleotides. Rapid Commun. Mass Spectrom. 20, 2348-2354 (2006)

29. Tromp, J.M., Schürch, S.: Gas-phase dissociation of oligoribonucleotides and their analogs studied by electrospray ionization tandem mass spectrometry. J. Am. Soc. Mass Spectrom. 16, 1262-1268 (2005)

30. Huang, T.Y., Kharlamova, A., Liu, J., McLuckey, S.A.: Ion trap collision-induced dissociation of multiply deprotonated RNA: c/y-ions versus (a-B)/w-ions. J. Am. Soc. Mass Spectrom. 19, 1832-1840 (2008)

31. Barry, J.P., Vouros, P., Vanschepdael, A., Law, S.J.: Mass and sequence verification of modified oligonucleotides using electrospray tandem mass spectrometry. J. Mass Spectrom. 30, 993-1006 (1995)

32. Farand, J., Beverly, M.: Sequence confirmation of modified oligonucleotides using chemical degradation, electrospray ionization, time-offlight, and tandem mass spectrometry. Anal. Chem. 80, 7414-7421 (2008)

33. Farand, J., Gosselin, F.: De novo sequence determination of modified oligonucleotides. Anal. Chem. 81, 3723-3730 (2009)

34. Monn, S.T.M., Schürch, S.: New aspects of the fragmentation mechanisms of unmodified and methylphosphonate-modified oligonucleotides. J. Am. Soc. Mass. Spectrom. 18, 984-990 (2007)

35. McLuckey, S.A., Habibigoudarzi, S.: Ion-trap tandem mass-spectrometry applied to small multiply-charged oligonucleotides with a modified base. J. Am. Soc. Mass. Spectrom. 5, 740-747 (1994)

36. Wang, B.H., Hopkins, C.E., Belenky, A.B., Cohen, A.S.: Sequencing of modified oligonucleotides using in-source fragmentation and delayed pulsed ion extraction matrix-assisted laser desorption ionization time-offlight mass spectrometry. Int. J. Mass Spectrom. 169, 331-350 (1997)

37. Ivleva, V.B., Yu, Y.Q., Gilar, M.: Ultra-performance liquid chromatography/tandem mass spectrometry (UPLC/MS/MS) and UPLC/MSE analysis of RNA oligonucleotides. Rapid Commun. Mass Spectrom. 24, 2631-2640 (2010)

38. Egger, A.E., Hartinger, C.G., Ben Hamidane, H., Tsybin, Y.O., Keppler, B.K., Dyson, P.J.: High resolution mass spectrometry for studying the interactions of cisplatin with oligonucleotides. Inorg. Chem. 47, 10626-10633 (2008)

39. Nyakas, A., Eymann, M., Schürch, S.: The influence of cisplatin on the gas-phase dissociation of oligonucleotides studied by electrospray ionization tandem mass spectrometry. J. Am. Soc. Mass Spectrom. 20, 792-804 (2009) 